\title{
Exergetic and Economic Assessment of Distillation Hybrid Configurations for Bioethanol Refining
}

\author{
B. Suleiman*, A.S Olawale ${ }^{+}$and S.M. Waziri ${ }^{+}$ \\ *Department of Chemical Engineering, Federal University of Technology Minna, Nigeria. \\ ${ }^{+}$Department of Chemical Engineering, Ahmadu Bello University Zaria, Nigeria \\ *Corresponding Author E-mail: bilyaminusuleiman@yahoo.com
}

\begin{abstract}
Thermo-economics analysis was used to identify the most economic distillation hybrid configuration to dehydrate bioethanol mash (12 wt \%) to fuel grade $(99.5 \mathrm{wt} \%)$ based on economic objective of minimization of operating cost in this work. Three different hybrids of THIDC with azeotropic and, extractive distillation units were assessed using similar feed and product specifications of $1200 \mathrm{kmol} / \mathrm{h}(12 \mathrm{wt} \%$ ethanol) and $55 \mathrm{kmol} / \mathrm{h}$ (99.5 wt\% ethanol) respectively. The six hybrid configurations were simulated using Aspen Plus ${ }^{\circledR}$. The hybrid of THIDC with conventional extractive distillation (THEX1) was shown to have the lowest irreversibility rate (lost work) and highest exergetic efficiency followed by the hybrid containing thermally extractive sequence (THEX3). The latter also has the lowest energy consumption. However, economic evaluation showed that thermally coupled extractive distillation hybrid (with THIDC) is the most attractive hybrid configuration dehydrating bioethanol to fuel grade at commercial scale with the highest return on investment (ROI) and the least annual product cost. This indicates its economic attractiveness when compared with the other hybrids considered in this work. The trade-off existing between economic and exergy efficiency favors the selection of THEX3 as the preferred choice for bioethanol refining among all the six hybrids investigated.
\end{abstract}

Keywords: Totally heat integrated distillation column; lost work; azeotropic distillation; extractive distillation; exergy efficiency; product cost.

\section{Introduction}

Anhydrous ethanol production has become one of the most important issues all over the world. This is due to the great efforts directed to the use of biofuels and reduction in pollution and environmental effects of fossil fuels.

The process of anhydrous ethanol production comprises three main steps: fermentation, distillation and dehydration [1]. Bioethanol can be produced from sugar, starch or cellulosic feed stock by fermentation. The major problem associated with refining of resulting ethanol to fuel grade is the energy consumption cost. The 10-20 wt $\%$ ethanol obtained after fermentation [2,3] could only be distilled to maximum of $95.6 \mathrm{wt} \%$ due to the formation of azeotrope; thus the removal of part or all of the remaining $4.4 \mathrm{wt} \%$ water to obtain fuel grade is usually carried out using one of the following separation techniques: azeotropic distillation, extractive distillation, pervaporation and pressure swing molecular sieves adsorption processes [4].

The use of hybrid separation systems provide means of achieving cheaper, easier and enhanced separation by linking distillation unit to any of the dehydration processes mentioned above.

Exergetic and economic analysis provides useful information for identification and quantitative measure of the thermodynamic imperfections in processes (as a result of production of entropy) as well as cost implication of the operations. The result of thermodynamic (exergy) analysis may be in line with those of economic analyses when the thermodynamic cost optimum takes precedence over maximum thermodynamic efficiency in process specification [5]. The ultimate aim of the analysis is to obtain an energy efficient process possessing minimum capital and operating cost.

Many works in this field focused on reduction in energy consumption and efficiency improvements of either a standalone unit or the hybrid unit (i.e. distillation and dehydration units). In the area of energy requirement several researchers worked to reduce energy consumption of either distillation stand alone or hybrid units containing azeotropic, extractive or pervaporation unit $[1,6,7,8,2]$. The hybrid configurations of distillation with three extractive sequences were compared based on energy requirement and second law efficiency on the basis of similar feed and product specifications [9]. Several attempts were made to study and investigate bioethanol refining using molecular sieves and to investigate the effects of several operating parameters for process improvements [10,11,12,13]. Bioethanol refining was also studied using hybrid distillation-pervaporation process and the serially connected module was chosen as the best [14]. In addition, distillation-pervaporation hybrid was studied using combined Aspen-Plus ${ }^{\circledR}$ and Excel visual basic for application which provided not only design tool but optimization procedure [15].

Furthermore, works in energy and economic analysis of bioethanol refining processes were carried out for the purpose of techno-economic comparison of energy usage between hybrids. Among such is the techno-economic comparison of energy usage between hybrids of azeotropic distillation and pervaporation with conventional distillation column [16]. It was found that the hybrid incorporating pervaporation consumes $52.4 \%$ less energy than that 
containing azeotropic distillation. Analysis was carried out to establish the most energy efficient among conventional, Petlyuk and thermally coupled extractive distillation sequences for bioethanol purification to $99.5 \mathrm{wt} \%$ [17]. Thermally extractive sequence recorded about $30 \%$ reduction in energy consumption. However, energy saving and capital cost evaluation in distillation column sequences with divided wall was carried out and showed that divided wall column gave significant energy reduction with less than $30 \%$ capital cost savings [18].

In all of these previous works the choice of the distillation column type that formed the hybrid with the dehydrating unit appeared to have been made arbitrarily.

However, totally heat integrated distillation column (THIDC) was identified as the best of the distillation column types for bioethanol separation [19]. The other four distillation column types studied were the simple conventional column, distillation column having intermediate heat exchanger with and without heat pump and secondary reflux and vaporization distillation column (SRVP). Comparison of various distillation based hybrid configurations that incorporate THIDC in terms of exergetic and economic performance has not been carried out for bioethanol refining. Therefore in this work different hybrid configurations of THIDC with azeotropic or extractive distillation unit were assessed from exergeticeconomic view point. Similar feed and product specifications were used for the six distillation hybrid configurations investigated.

\section{Methodology}

Three azeotropic and extractive distillation configurations were selected from the works reported in the literature $[7,16,9,2]$. For the two dehydrating distillation processes, the selected configurations were the conventional column and two other integrated configurations which perform relatively very well in term of product purity, throughputs and energy consumption. They were individually connected to THIDC (using feed at $102{ }^{\circ} \mathrm{C}$ ) to obtain the hybrid configurations for dehydrating the water-ethanol mixture. These six hybrid configurations were subjected to simulation using Aspen Plus ${ }^{\circledR}$ to generate data for exergy and economic analysis. The six configurations were then ranked in order to select the best configuration based on economic consideration.

\subsection{Simulation of THIDC-Azeotropic Distillation Hybrid Configurations}

Three different types of azeotropic distillation columns (as shown in Figures 1-3) were used to form hybrid with THIDC which was identified as the best [19]. The configurations were those whose recycle stream enters into: (a) azeotropic column with organic phase (Figure 1), (b) the azeotropic column along with fresh feed (Figure 2), (c) the decanter (Figure 3). These three azeotropic units have been identified as the best [2].

In all cases a Radfrac column type was selected from Aspen-Plus ${ }^{\circledR}$ window in developing each flow sheet. The simulated THIDC column was replicated by exporting the developed flow sheet to a new Aspen-Plus ${ }^{\circledR}$ simulation environment. The third component - an entrainer (cyclohexane) - was added in the components list specified for the system. Though, benzene is more favourable economically and energy-wise it is not used anymore because of its environmental consequences [2]. The rectification column (THIDC) distillate $(67.9 \mathrm{kmol} / \mathrm{h})$ was connected as the feed stream into each of the three azeotropic distillation column types either as separate feed or combined feed with the recycle stream containing 99.5 wt $\%$ ethanol. See Figure 1 as an example.

Each of the azeotropic section consists of dehydration and azeotropic column having internal decanter with the exception of the configuration whose recycle stream was connected to an external decanter (Figure 3). The azeotropic distillate products were cooled in a condenser and split into aqueous and organic phase in the decanter. In all simulations, a feed flow rate of $1200 \mathrm{kmol} / \mathrm{h}(12 \mathrm{wt} \%$ ethanol) into THIDC and azeotropic column bottoms products of $52 \mathrm{kmol} / \mathrm{h}$ (99.5 wt\% ethanol) was maintained. In addition, the tray sizing, required block and stream specifications to the azeotropic section were provided and the three hybrid configurations were rigorously simulated. The simulation result obtained was transferred to Microsoft excel $^{\circledR}$ (Microsoft office suite) for use in subsequent analysis.

\subsection{Simulation of THIDC-Extractive Distillation Hybrid Configurations}

Three different configurations of extractive distillation were used to form hybrid with totally heat integrated distillation column (THIDC). They were the hybrids containing: (a) conventional extractive distillation (Figure 4), (b) Petlyuk column and (c) thermally coupled column (Figure 6). The THIDC unit specifications were kept fixed with little interaction as the case may be with its downstream.

The hybrid units were simulated as follows: The simulated THIDC column was replicated in a new Aspen Plus ${ }^{\circledR}$ simulation environment and a third component entrainer (ethylene-glycol) was added in the components list specified for the system. The choice of this entrainer was based on its low cost, good capacity and selectivity [21]. THIDC rectification distillate $(67.9 \mathrm{kmol} / \mathrm{h}$ containing 95.5 wt\% ethanol) was connected as the feed stream to extractive columns of configurations 1 and 3 (Figuren 1 and 3 . For configuration 2 (Figure 2), it was entering as the feed into Petlyuk column. The entrainer stream was recovered as bottom product of the extractive columns of configuration 2 and 3 but recovered as bottom products of the recovery column of configuration 1 .

Radfrac column type was used for the simulation and extractive column distillate products were maintained as ethanol $(99.5 \mathrm{wt} \%)$. The destination stage and flow rate of intermediate streams withdrawn as feed to another column were specified and adjusted throughout the simulation. In addition, the flow sheets were completed and all required streams and blocks variables were specified while column tray sizing and report option was made in a similar way to that of the THIDC column. In all simulations, feed flow rate of $1200 \mathrm{kmol} / \mathrm{h}$ (12 wt\% ethanol) into THIDC and extractive column distillate products of $52 \mathrm{kmol} / \mathrm{h}$ containing $99.5 \mathrm{wt} \%$ ethanol were maintained. The developed flow sheets were rigorously simulated until convergence was achieved.

In the entire hybrid configurations (Figures 1-6), similar product and feed specifications were used for the purpose 
of comparing the configurations on the same basis. This allows selection of variables of the column and other equipment to achieve the target specification. The input parameters into the Aspen Plus ${ }^{\circledR}$ for all the configurations are shown in Table 2.

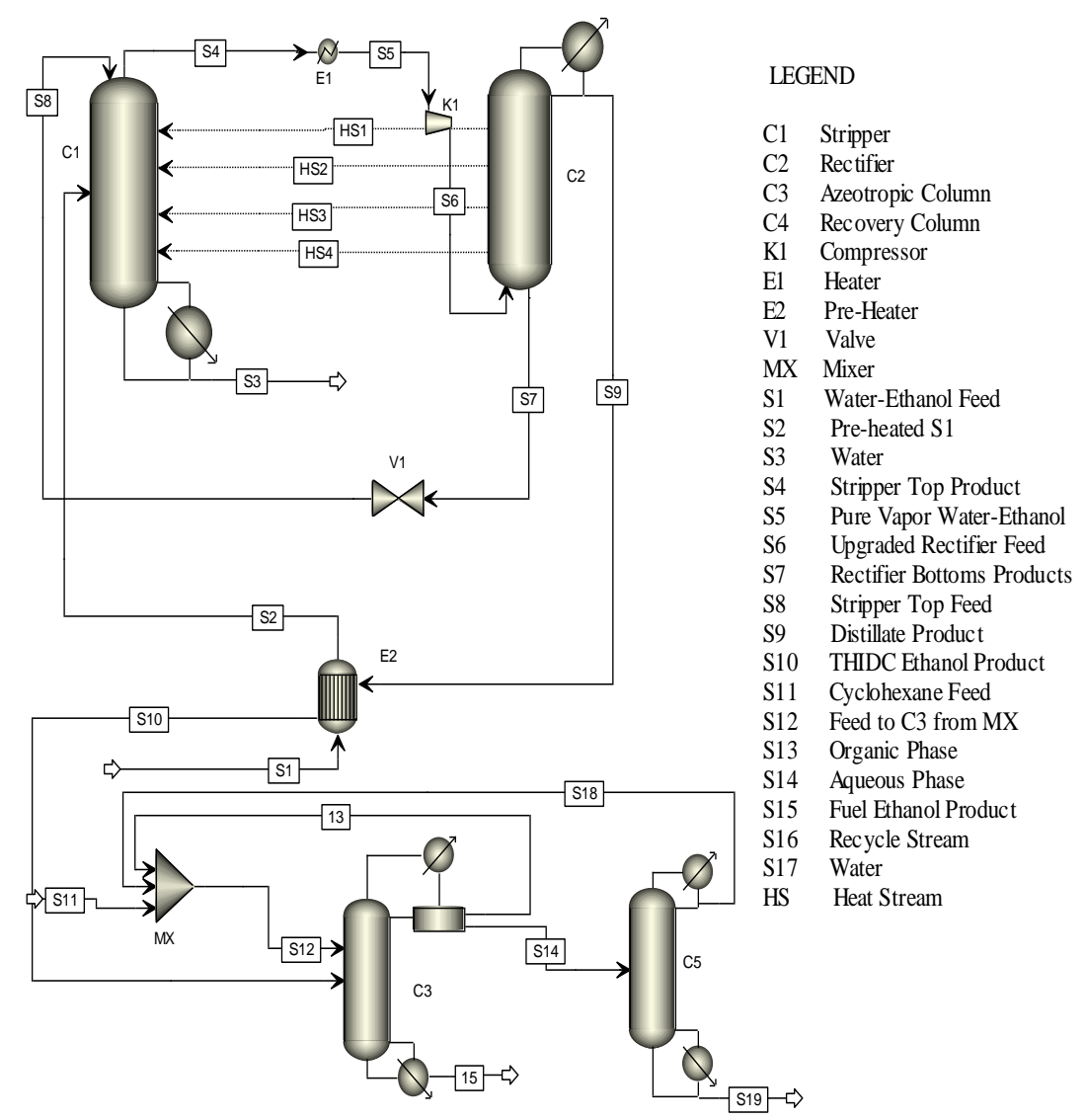

Figure 1. THIDC-Azeotropic Distillation Hybrid with Recycle Stream Mixing and Entering with Organic Phase (THAZ1)

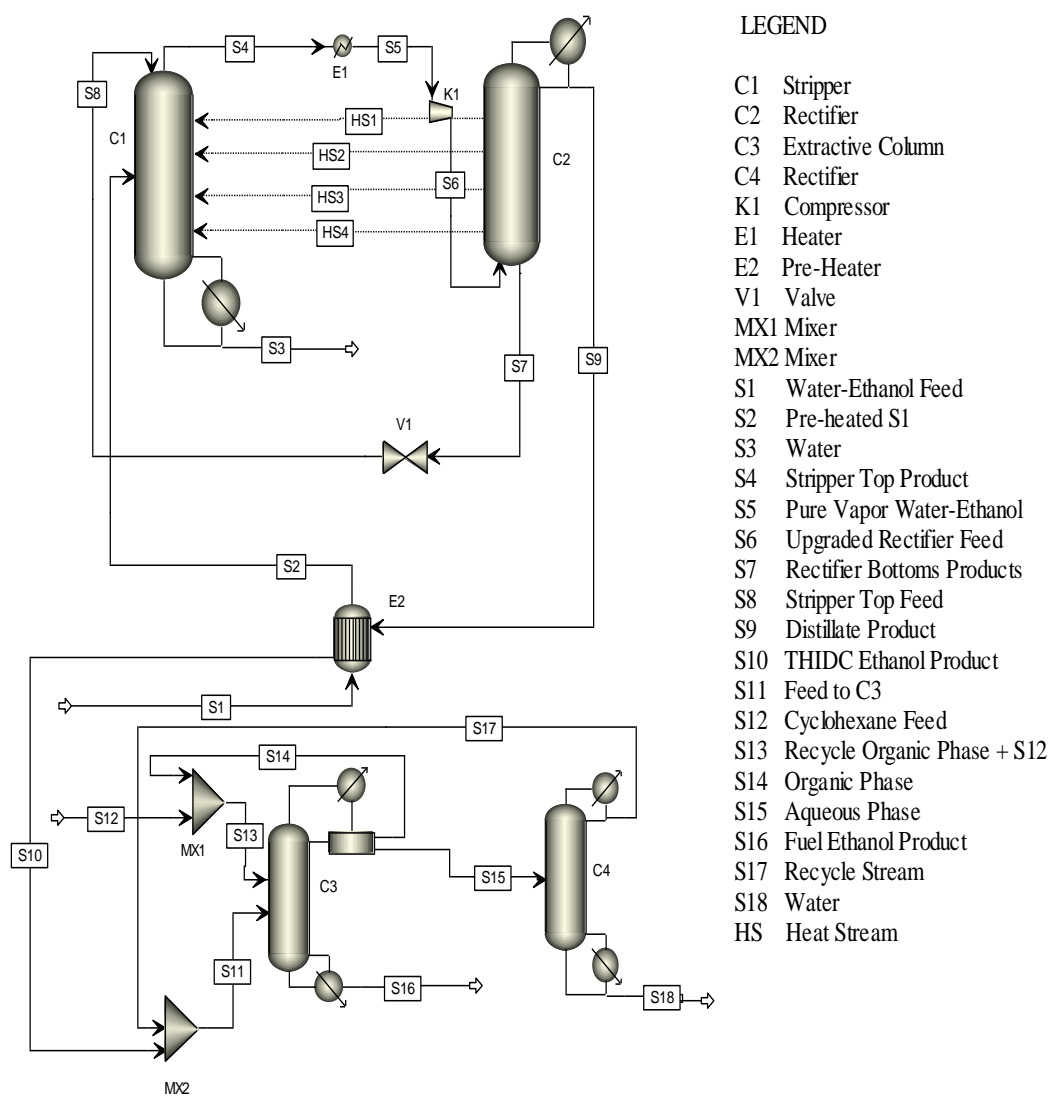

Figure 2. THIDC-Azeotropic Distillation Hybrid with Recycle Stream Mixing and Entering with Feed (THAZ2) 


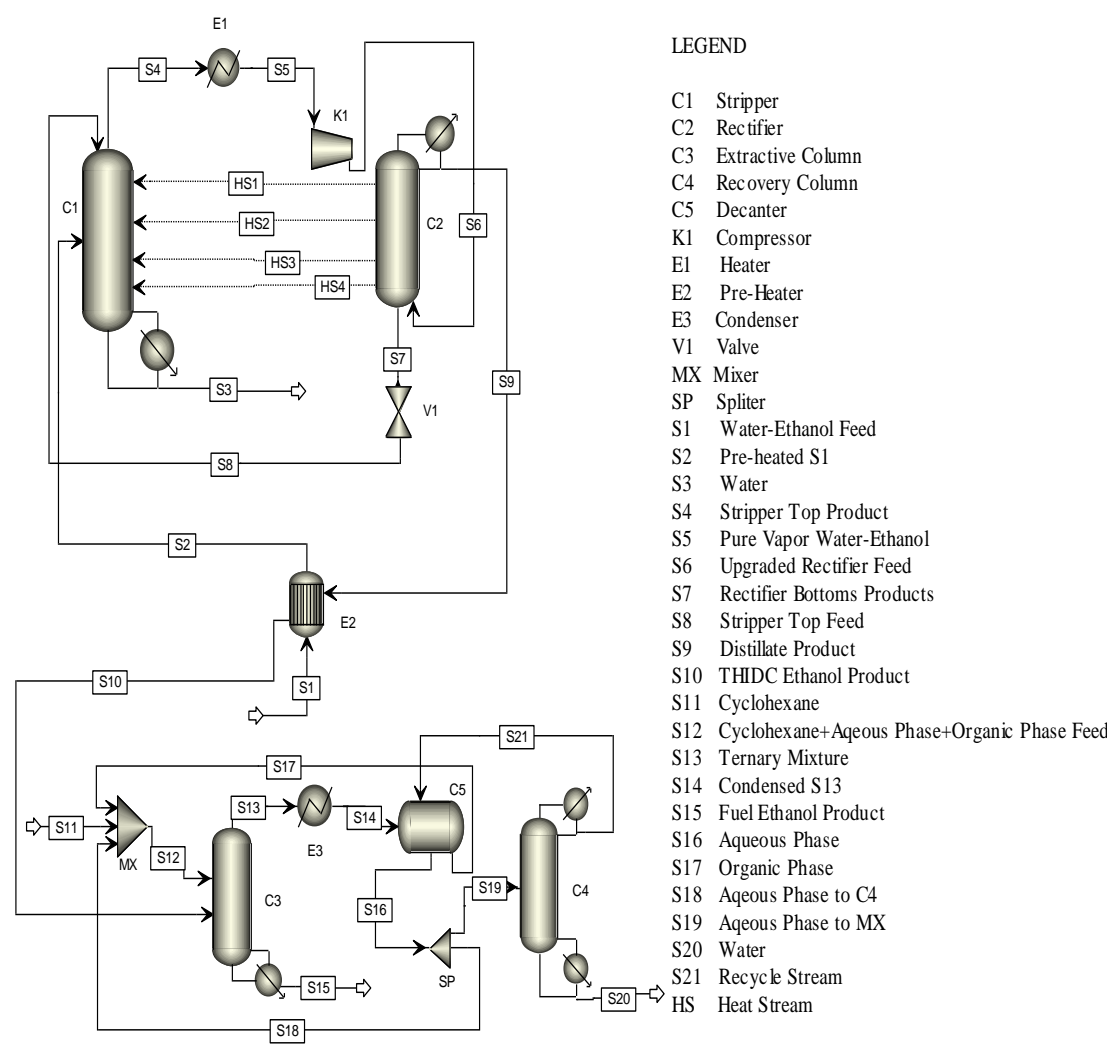

Figure 3. THIDC-Azeotropic Distillation Hybrid with recycle Stream Entering into Decanter

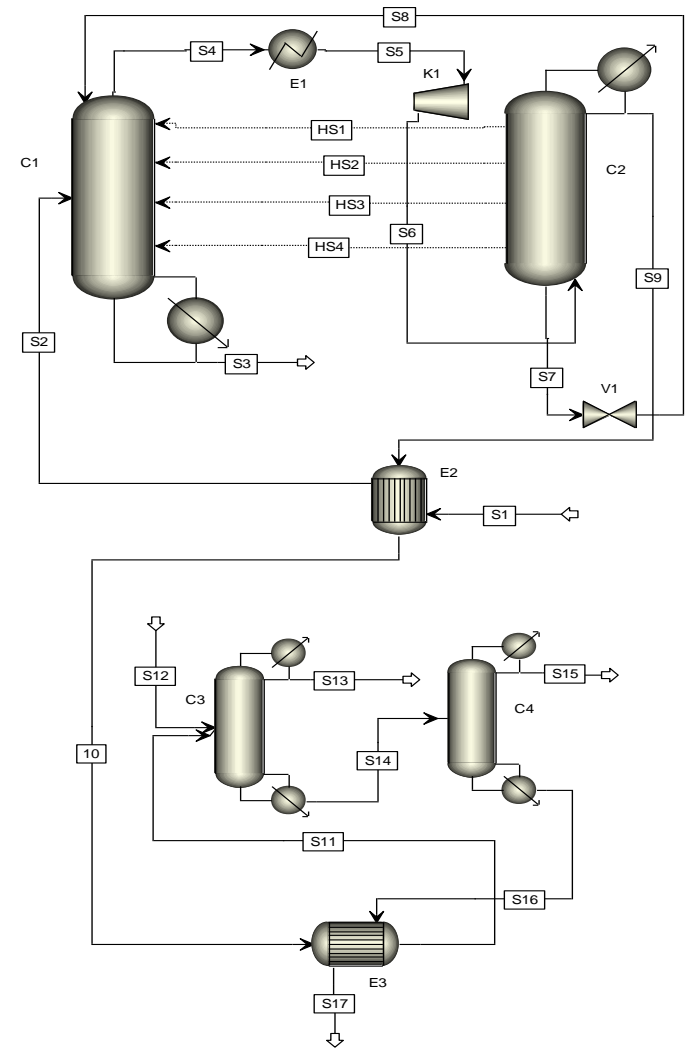

LEGEND

C1 Stripper

C2 Rectifier

C3 Extractive Column

C4 Recovery Column

K1 Compressor

El Heater

E2 2 Pre-Heater

V1 Valve

S1 Water-Ethanol Feed

S2 Pre-heated S1

S4 Stripper Top Product

S5 Pure Vapor Water-Ethanol

S6 Upgraded Rectifier Feed

S7 Rectifier Bottoms Products

S8 Stripper Top Feed

S9 Distillate Product

S10 THIDC Ethanol Product

S11 Preheated Feed to C3

S12 Eyhylene-Glycol Feed

S13 Fuel Ethanol Product

S14 Water-Ethanol-Ethly-Glycol to C4

S15 Water-Ethanol Mixture

S17 Ethylene Glycol

Figure 4. THIDC-Conventional Extractive Distillation Hybrid (THEX1) 


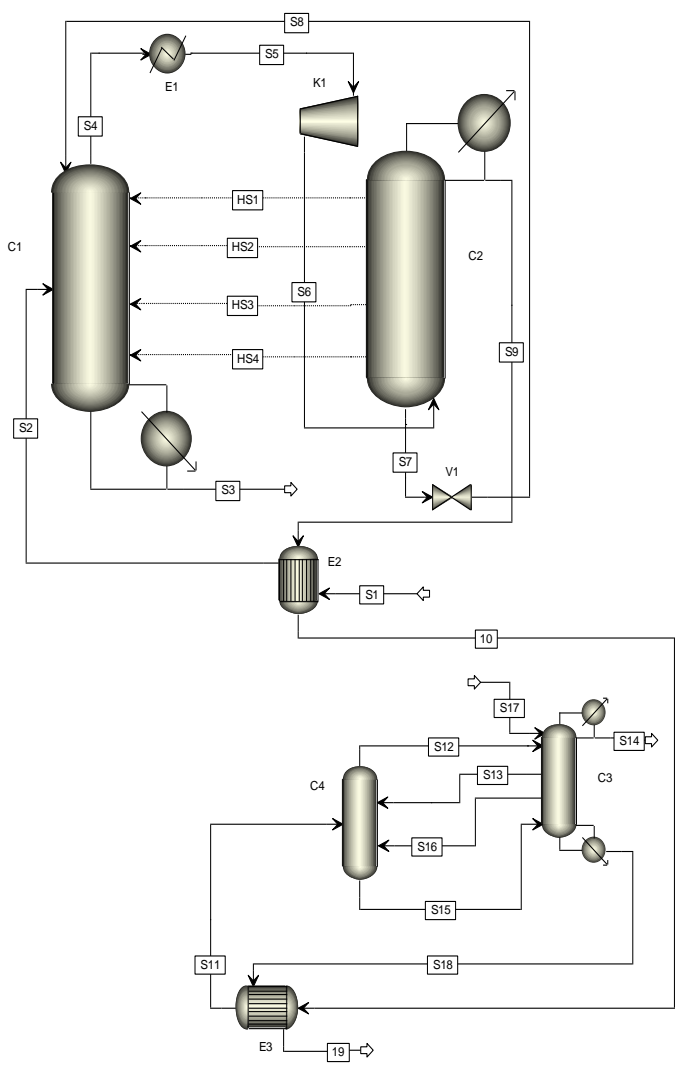

LEGEND

C1 Stripper

22 Rectifier

C4 Petlyuk Column

K1 Compressor

E1 Heater

E2 Pre-Heater

E3 Pre-Heater

V1 Valve

S1 Water-Ethanol Feed

S2 Pre-heated S1

S3 Water

S4 Stripper Top Product

5 Pure Vapor Water-Ethanol

Upgraded Rectifier Feed

Rectifier Bottoms Products

8 Stripper Top Feed

S9 Distillate Product

S10 Ethanol Product

12 Petlyuk Column Vapor

S13 Petlyuk Column Top Liquid InLET

S14 Ethanol Product

S15 Petlyuk Column Bottom Liquid

S16 C3 Side draw

S17 Ethylene Glycol Feed

S18 Ethylene Glycol out
S19 Ethylene Glycol Recovere

HS Heat Stream

Figure 5. THIDC-Petlyuk Column Extractive Distillation Hybrid (THEX2)

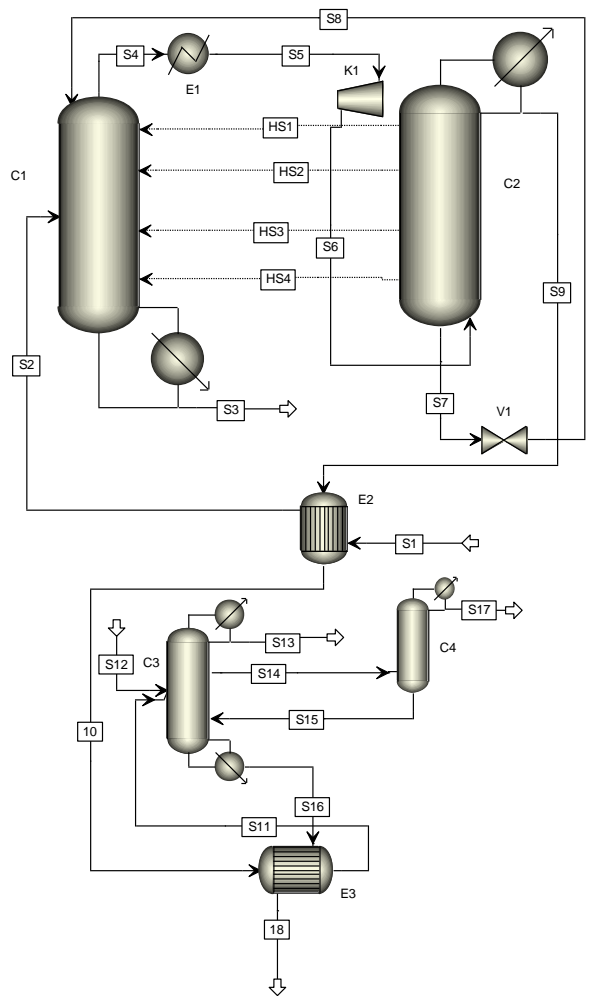

LEGEND

C1 1 Stripper

C3 3 Extractive Column

C4 Rectifier

K1 Compresso

E1 Heater

E2 Pre-Heater

V1 Valve

S1 Water-Ethanol Feed

S2 Pre-heated S1

S3 Water

S4 Stripper Top Product

S5 Pure Vapor Water-Ethanol

S6 Upgraded Rectifier Feed

S7 Rectifier Bottoms Product

$\begin{array}{ll}\text { S7 } & \text { Rectifier Bottoms P } \\ \text { S8 } & \text { Stripper Top Feed }\end{array}$

S9 Distillate Product

S10 THIDC Ethanol Product

S11 Preheated Feed to C3

S12 Eyhylene-Glycol Feed

S13 Fuel Ethanol Product

S14 Water-Ethanol- Ethyl-Glyc ol Mixture to C4

S15 C4 Bottoms Product

S16 Ethylene Glyc ol

S17 Ethanol-Water Mixture

S18 Ethylene Glycol to Recycle

HS Heat Stream

Figure 6. THIDC-Thermally Coupled Extractive Distillation Hybrid (THEX3)

\subsection{Energy and Exergy Analysis of Hybrid \\ Configurations}

The data obtained from simulation of the hybrid configurations for water-ethanol mixture dehydration were used for energy and exergy analyses with Microsoft Excel spread sheet software. The parameters determined were streams' physical and chemical exergy, lost work and exergy efficiency.

The physical exergy $\dot{\mathrm{B}}_{\text {phy }}(\mathrm{kJ} / \mathrm{sec})$ of a stream of matter with flow in enthalpy $\mathrm{h}(\mathrm{kJ} / \mathrm{sec})$ and entropy $\dot{\mathrm{s}}(\mathrm{kJ} / \mathrm{K}$. sec) at $\mathrm{T}$ and $\mathrm{P}$, relative to the surroundings (dead state) at $\mathrm{T}_{\mathrm{o}}$ and $\mathrm{P}_{\mathrm{o}}$ was determined using Eq. 1[21]. 


$$
\dot{\mathrm{B}}_{p h y}=\left[\mathrm{h}(T, P)-\mathrm{h}\left(T_{o}, P_{o}\right)\right]-T_{o}\left[\dot{\mathrm{s}}(T, P)-\dot{\mathrm{s}}\left(T_{o}, P_{o}\right)\right]
$$

The chemical exergy $\dot{\mathrm{B}}_{\text {chem }}(\mathrm{kJ} / \mathrm{sec})$ of each stream of matter with component mole fraction $x_{i}$ ( $y_{i}$ for vapour) and standard chemical exergy $\dot{\mathrm{e}}_{i}^{o}(\mathrm{~kJ} / \mathrm{sec})$ of each component $i$ in a stream was evaluated using Eq. 2 [21].

$\dot{\mathrm{B}}_{\text {chem }}=\sum x_{i} \dot{\mathrm{e}}_{i}^{O}$

The total stream exergy $\dot{\mathrm{B}}_{\text {total }}$ in Eq. 3 was evaluated as the sum of its physical $\left(\dot{\mathrm{B}}_{\text {phy }}\right)$ and chemical exergy $\left(\dot{\mathrm{B}}_{\text {chem }}\right)$.

$$
\dot{\mathrm{B}}_{\text {total }}=\dot{\mathrm{B}}_{\text {phy }}+\dot{\mathrm{B}}_{\text {chem }}
$$

The lost work LW, around each piece of equipment or for overall configuration with streams flows $\dot{\mathrm{m}}(\mathrm{kg} / \mathrm{s})$, streams exergy B $(\mathrm{kJ} / \mathrm{kg})$, work flows $\dot{\mathrm{W}}(\mathrm{kJ} / \mathrm{s})$, utility heat duties $Q$ $(\mathrm{kJ} / \mathrm{s})$ at actual temperature $\mathrm{T}(\mathrm{K})$ and reference state temperature $T_{0}(\mathrm{~K})$ was evaluated using Eq. 4 [22].

$$
\begin{aligned}
& L \dot{\mathrm{W}}=\Sigma(\dot{\mathrm{m}} B)_{\text {in }}-\Sigma(\dot{\mathrm{m}} B)_{\text {out }}+\Sigma \dot{\mathrm{W}}_{\text {in }}-\Sigma \dot{\mathrm{W}}_{\text {out }}+ \\
& \Sigma\left[Q\left(1-\frac{T_{0}}{T}\right)\right]_{\text {in }}-\Sigma\left[Q\left(1-\frac{T_{0}}{T}\right)\right]_{\text {out }}
\end{aligned}
$$

In addition, exergetic efficiency $\left(\eta_{\text {Exergetic }}\right)$ was evaluated around equipment and for each hybrid configuration. The exergetic efficiency is the ratio of the exergy recovered $\sum \dot{\mathrm{B}}_{\text {out }}$ (total output exergy) to the total input exergy $\sum \dot{\mathrm{B}}_{\text {in }}$ as given in Eq. 5 [23].

$$
\eta_{\text {Exergetic }}=\frac{\left.\sum \text { (Exergy out }\right)}{\Sigma(\text { Exergy in })}
$$

\subsection{Economic Analysis of Hybrid Configurations}

Economic analysis of each of the successfully converged six hybrid configurations was carried out in stages. The first stage was the evaluation of all capital cost of each configuration. Secondly all annual utility, material requirement and cost were determined and subsequently the economic evaluation. However, the whole economic analysis was carried out using the approach developed for chemical plant economic evaluation [24]. Therefore, using this approach, fixed capital and working capitals were obtained using percentage of equipment delivery method.

In addition, parameters in Table 1 were used in the evaluation of materials input cost, equipment cost, utility cost and annual total product sales. However, the utility requirement and its cost was obtained from the Aspen Plus by specifying the heating/cooling duty $(\mathrm{kJ} / \mathrm{kg})$, inlet and outlet utility temperature as well as purchased price. The duty of a utility with specific heat capacity $C_{p} \quad(\mathrm{~kJ} / \mathrm{kg} \quad \mathrm{K})$ and temperature difference $\Delta T$ between its inlet and outlet was obtained from the energy balance equation as the product $C_{p} \times \Delta T$.

All costs and products value were subjected to profitability analysis using online spread sheet for chemical plant economic evaluation [27]. Equations used to evaluate profitability parameters are contained in plant design and economics for chemical engineers [25] and the spreadsheets for carrying out this analysis are available online [27].

Table1. Parameters Assumed for Economic Analysis

\begin{tabular}{lll}
\hline S/N & Parameter & Value \\
\hline 1 & Operating time (days/yr.) & 335 \\
2 & Equipment cost basis (CEPCI) & 2012 \\
3 & Desired product ethanol cost $(\$ / \mathrm{kg})$ & 4.0 \\
4 & Steam cost (Medium pressure, $\$ / \mathrm{kg})$ & 0.00966 \\
5 & Cooling water cost $(\$ / \mathrm{kg})$ & 0.00063 \\
6 & Cyclohexane cost $(\$ / \mathrm{kg})$ & 0.37 \\
7 & Ethylene glycol cost $(\$ / \mathrm{kg})$ & 0.39 \\
8 & Input ethanol cost $(\$ / \mathrm{kg})$ & 0.02 \\
\hline
\end{tabular}


Table2. Aspen Plus Input Parameters for Simulation of the Hybrids

\begin{tabular}{|c|c|c|c|c|c|c|}
\hline \multirow[t]{2}{*}{ Parameter } & \multicolumn{6}{|c|}{ Value } \\
\hline & THEX1 & THEX2 & THEX3 & THAZ1 & THAZ2 & THAZ3 \\
\hline Fermenters feed flow $(\mathrm{kmol} / \mathrm{h})$ & 1200 & 1200 & 1200 & 1200 & 1200 & 1200 \\
\hline Azeotropic feed flow (kmol/h) & 67.9 & 67.9 & 67.9 & 67.9 & 67.9 & 67.9 \\
\hline Separating agent flow $(\mathrm{kmol} / \mathrm{h})$ & 27.3 & 36.364 & 19.5 & 14 & 30.3 & 10.34 \\
\hline Extractive column's distillate flow $(\mathrm{kmol} / \mathrm{h})$ & 52 & 52 & 52 & - & - & - \\
\hline Azeotropic column's bottoms flow $(\mathrm{kmol} / \mathrm{h})$ & - & - & - & 52 & 52 & 52 \\
\hline Molar fraction of fuel-ethanol & 0.9899 & 0.9899 & 0.9899 & 0.9899 & 0.9899 & 0.9899 \\
\hline Temperature of fermenters feed $\left({ }^{\circ} \mathrm{C}\right)$ & 102 & 102 & 102 & 102 & 102 & 102 \\
\hline Temperature of azeotropic feed $\left({ }^{\circ} \mathrm{C}\right)$ & 105.15 & 105.15 & 105.15 & 106.14 & 106.14 & 106.14 \\
\hline Temperature of separating agent $\left({ }^{\circ} \mathrm{C}\right)$ & 85 & 85 & 85 & 80 & 80 & 80 \\
\hline Molar reflux ratio in rectifier column & 4.8 & 4.8 & 4.8 & 5 & 5 & 5 \\
\hline Molar reflux ratio in extractive column & 0.359 & 0.356 & 0.455 & - & - & - \\
\hline Molar boil-up ratio in stripper column & 0.148 & 0.149 & 0.148 & 0.148 & 0.148 & 0.148 \\
\hline Molar boil-up ratio in azeotropic column & - & - & - & 8.541 & 6.973 & 2.95 \\
\hline Number of theoretical stages ( $\mathrm{C} 1$ column) & 30 & 30 & 30 & 30 & 30 & 30 \\
\hline Number of theoretical stages ( $\mathrm{C} 2$ column) & 27 & 27 & 27 & 27 & 27 & 27 \\
\hline Number of theoretical stages ( $\mathrm{C} 3$ column) & 40 & 48 & 38 & 70 & 74 & 80 \\
\hline Number of theoretical stages ( $\mathrm{C} 4$ column) & 12 & 8 & 8 & 12 & 8 & 9 \\
\hline Fermenters feed stage & 15 & 15 & 15 & 15 & 15 & 15 \\
\hline Azeotropic feed stage & 28 & 3 & 27 & 45 & 9 & 65 \\
\hline Pressure in the $\mathrm{C} 1$ column (atm) & 1.0023 & 1.0023 & 1.0023 & 1.0023 & 1.0023 & 1.0023 \\
\hline Pressure in the $\mathrm{C} 2$ column (atm) & 17 & 17 & 17 & 19 & 19 & 19 \\
\hline Pressure in the C3 column (atm) & 1.21 & 1.6 & 3.01 & 2.6 & 2.55 & 1.12 \\
\hline Pressure in the $\mathrm{C} 4$ column (atm ) & 1.0 & 1.6 & 3.0 & 1.12 & 0.7 & 1.1 \\
\hline Pressure in the decanter (atm) & - & - & - & 2.6 & 1.1 & 1.0 \\
\hline Separating-agent feed stage & 3 & 4 & 3 & 7 & 7 & 6 \\
\hline Solvent/feed ratio $(\mathrm{S} / \mathrm{F})$ & 0.402 & 0.54 & 0.287 & $2 \mathrm{E}-6$ & 0.446 & 0.1523 \\
\hline Feed stage of aqueous mixture & - & - & - & 8 & 6 & 4 \\
\hline Compressor power requirement $(\mathrm{kW})$ & 917.5 & 917.5 & 917.5 & 958.7 & 958.7 & 958.7 \\
\hline Exchanger 1 duty $(\mathrm{kW})$ & 25.31 & 25.31 & 25.31 & 23.87 & 23.87 & 23.87 \\
\hline Exchanger 2 duty $(\mathrm{kW})$ & 63.22 & 63.22 & 62.22 & 60.29 & 60.29 & 60.29 \\
\hline Exchanger 3 duty $(\mathrm{kW})$ & 5.21 & 4.617 & 22.19 & - & - & - \\
\hline
\end{tabular}

\section{Results and Discussion \\ 3.1 Energy and Exergy Analysis}

Tables 3-6 show the energy and exergy analysis result for the six hybrid configurations selected in this work. The material streams and utility exergy flows in and out were used to carry out exergy analysis for each of the hybrid unit. The various streams exergy results include the contributions of physical and chemical exergy evaluated using Eq. (1) and (3). The exergy of mixing was included in physical exergy evaluation since the respective streams entropies were used.

Table3. Total Input Energy, Exergy efficiency and Lost Work for all Hybrids

\begin{tabular}{lrrr}
\hline Configuration & $\begin{array}{r}\text { Input energy } \\
(\mathrm{kW})\end{array}$ & $\begin{array}{r}\text { Lost work } \\
(\mathrm{kW})\end{array}$ & $\begin{array}{r}\text { Exergy } \\
\text { Efficiency } \\
\text { (fraction) }\end{array}$ \\
\hline THAZ1 & 37700 & 13400 & 0.583 \\
THAZ2 & 69700 & 39900 & 0.383 \\
THAZ3 & 47900 & 23000 & 0.466 \\
THEX1 & 39200 & 2644 & 0.927 \\
THEX2 & 42202 & 4010 & 0.901 \\
THEX3 & 36666 & 2730 & 0.918 \\
\hline
\end{tabular}

Table 3 shows the energy and exergy analysis results for the six different hybrid configurations formed by linking THIDC to azeotropic and extractive distillation units. The total input energy includes energy associated with material feed as well as thermal and work energy inputs. The THIDC-extractive sequences hybrids are shown to be the most efficient. The least efficient hybrid was THAZ2 with the highest lost work and least exergy efficiency. The table also shows that THEX3 hybrid had the lowest energy requirement while THEX1 recorded the least lost work and highest exergetic efficiency of $92.7 \%$ followed by THEX3.

Table 3 shows the result of exergetic efficiency and lost work for the hybrid configurations. Meanwhile, Tables 4 and 5 shows the exergy efficiency across the constituent equipment/devices of the hybrids. As it is expected, the results show that the higher the aggregate exergetic efficiency across the units the smaller the lost work (irreversibility). These values indicate the work potentials of the material or energy stream. Considering THEX1 which is the most energy efficient hybrid, the exergetic efficiency of most of the equipment in the flow sheet were around $99 \%$ with the exception of valve, stripper (C1) and rectifier (C2). This trend was observed with the other five hybrids. This indicates a greater need for improved equipment design in the THIDC section.

The least energy efficient hybrid, THAZ2, was observed to have the highest exergy losses at the extractive column, recovery column (C3), heat exchanger E2 and valve as shown in Table 4. Selection of heat transfer media possessing excellent thermal and transport properties should improve efficiency of heat exchanger.

The loss of exergy in mixers and columns, particularly in the dehydration unit of most of the hybrids is mainly due to the change in composition from inlet to the outlet stream. 
This loss resulting from exergy change of mixing can be addressed by blending as much as possible streams of nearly similar compositions. The low exergetic efficiency of some columns is due to inevitable change in composition across these units.

Similar values were across the hybrids investigated with most of the equipment of THIDC unit. This was more prominent in the hybrids containing extractive sequences. The reason for this has to do with similar operating conditions used with the THIDC equipment and auxiliaries. Meanwhile, it is different for hybrid containing azeotropic distillation units because of the slight interactions between THIDC and the dehydration unit.

A look at the two most energy efficient hybrids (THEX1and THEX3), brought to the fore the possibility that distillation column may have high exergy loss but very high or low exergetic efficiency as pointed out ealier [25]. THEX3 has higher exergy loss and lower energy requirement than THEX1 yet the latter is exegetically more efficient. The results also show that a process requiring less energy is not necessarily more efficient than the one with greater energy input if the former process is more efficient in its energy utilization.

Table 4. Equipment Exergy Efficiency for Azeotropic Hybrids.

\begin{tabular}{lccc}
\hline Equipment & \% Equipment Exergy Efficiency \\
& THAZ1 & THAZ2 & THAZ3 \\
\hline Stripper (C1) & 97.64 & 97.64 & 97.33 \\
E1 & 99.99 & 99.99 & 99.99 \\
Compressor & 99.50 & 99.50 & 99.48 \\
Rectifier (C2) & 93.54 & 93.43 & 93.74 \\
Valve & 93.24 & 93.24 & 93.35 \\
E2 & 91.64 & 91.64 & 91.64 \\
Mixer & 99.53 & 99.96 & 99.87 \\
Column C3 & 88.50 & 47.74 & 81.50 \\
Column C4 & 54.00 & 39.21 & 96.91 \\
Splitter/Mixer & - & 99.98 & 99.96 \\
E3-condenser & - & - & 98.80 \\
Decanter & - & - & 99.96 \\
\hline
\end{tabular}

Table 5. Equipment Exergy Efficiency for Extractive Hybrids.

\begin{tabular}{lccc}
\hline Equipment & \multicolumn{3}{c}{ Equipment Exergy Efficiency } \\
& THEX1 & THEX2 & THEX3 \\
\hline Stripper (C1) & 97.65 & 97.65 & 97.65 \\
E1 & 99.99 & 99.99 & 99.99 \\
Compressor & 99.51 & 99.51 & 99.51 \\
Rectifier (C2) & 93.65 & 93.64 & 93.64 \\
Valve & 95.81 & 95.81 & 95.81 \\
E2 & 99.98 & 99.98 & 99.98 \\
E3 & 99.99 & 99.98 & 99.98 \\
Column C3 & 99.49 & 99.55 & 99.27 \\
Column C4 & 99.81 & 96.57 & 95.15 \\
\hline
\end{tabular}

THIDC-extractive distillation hybrids recorded the least energy consumption and lost work among all the hybrids. The THEX1 hybrid is the most energy efficient followed by comparison with THEX 2 and THEX3 hybrid in that order. Though, the energy consumption and lost work did not differ much among the three, but THEX3 is the least energy requiring. Previous works that used conventional column with the same extractive sequences but identified hybrid with Petlyuk column as the most energy efficient and least energy consuming [9]. Comparing the results in this work and other work [9] that used conventional distillation column (as part of the hybrid) showed energy cost savings of 70,71 and $58.3 \%$ in processing a kilogram of the feed using THEX1, THEX2 and THEX3 respectively (see Table 6). The improvement recorded in this work can also be linked to the use of THIDC.

The exergy analysis has placed THIDC-Conventional extractive distillation hybrid as the best hybrid. It has the least lost work (irreversibility rate) and highest exergy efficiency followed by THEX3 and THEX2 in that order. The least in term of thermodynamic potential are the hybrids with azeotropic dehydration units.

Comparative analysis based on energy consumption from input utility streams show that a reasonable improvement was achieved in this work. In comparison to a previous

Table 6. Comparative Energy Consumption (Present and Previous Studies)

\begin{tabular}{|c|c|c|c|c|c|}
\hline \multicolumn{2}{|c|}{ Current Studies } & \multicolumn{2}{|l|}{ Previous Studies } & \multirow[b]{2}{*}{$\begin{array}{l}\% \text { Energy cost } \\
\text { savings }\end{array}$} & \multirow[b]{2}{*}{ Basis } \\
\hline $\begin{array}{c}\text { Hybrid } \\
\text { Configuration }\end{array}$ & $\begin{array}{c}\text { Energy } \\
\text { Consumed } \\
(\mathrm{MJ} / \mathrm{kg})\end{array}$ & $\begin{array}{c}\text { Hybrid } \\
\text { Configuration }\end{array}$ & $\begin{array}{c}\text { Energy } \\
\text { Consumed } \\
(\mathrm{MJ} / \mathrm{kg})\end{array}$ & & \\
\hline THEX 1 & 0.56 & Conventional distillation - EX1 [9] & 1.86 & 70 & Feed \\
\hline THEX 2 & 0.56 & Conventional distillation - EX2 [9] & 1.89 & 71 & Feed \\
\hline THEX 3 & 0.57 & Conventional distillation - EX3 [9] & 1.38 & 58.3 & Feed \\
\hline THEX 1 & 5.44 & Conventional distillation - EX1 [8] & 10.69 & 49.1 & Product \\
\hline THAZ 1 & 9.14 & Conventional distillation - AZ1 & 12.38 & 32.4 & Product \\
\hline
\end{tabular}


[8], Table 6 shows that there were 49.1 and $32.4 \%$ cost savings respectively in using THEX1 and THAZ 1 hybrid to produce a kilogram of $99.5 \mathrm{wt} \%$ anhydrous fuel ethanol. The reduction in energy consumption achieved in all cases could be attributed to the use of THIDC which has been found to be relatively efficient distillation column type [26, 19]. This column used higher grade energy (work) to achieve desired separation enrichment of bioethanol mash to azeotropic mixture. However, the study of the feed thermal condition allowed the choice of optimal THIDC feed condition [19].This might be another reason for the observed improvement.

\subsection{Economic Analysis}

Figure 7 shows the various cost elements of each of the hybrids. Though, the feed and desired product specifications were the same but side products, recycle streams and entrainer specifications were not. This disparity could explain, in part, the variation in total annual products sales (TAPS) among the hybrids.

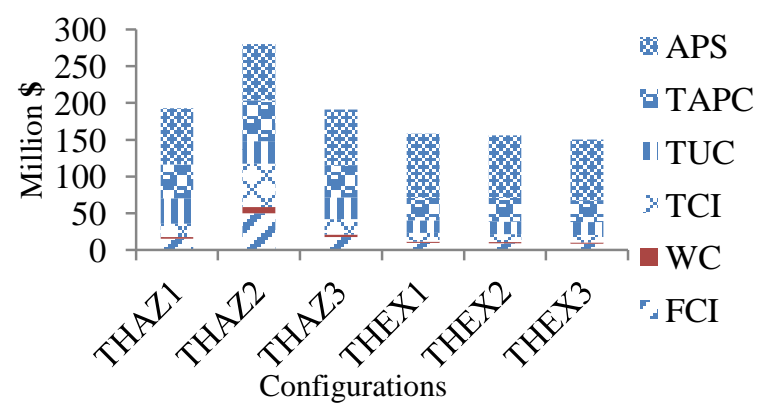

Figure 7. Product Sales and Cost Analysis Result of Hybrid Configurations

The THIDC-azeotropic sequences recorded the least total annual product sales (TAPS) of only $\$ 76.91$ million because the by-product value was less. The hybrid with the highest TAPS was THEX1 with $\$ 87$ million. THAZ3 had the least annual product cost of \$29.4 million followed by THAZ1 and THAZ2 in that order. THAZ2 had the highest annual product cost.

Profitability analysis shows that THIDC-extractive sequences hybrids are the most attractive configurations for the refining of bioethanol to fuel grade (see Figures 8 to 11). The profitability analysis showed THEX 3 as the most favorable. It had the highest return on investment (ROI), maximum annual and continuous discounted cash flow rate (ADCR and CDCR) of $114 \% / y e a r$ and $76.1 \% / y e a r$ respectively (Figure 8). It also has the least payback period (see Figure 10). The second and third best were THEX1 and THEX2 respectively. THAZ2 is the least economic hybrid configuration of the six. The net present worth was in favor of THEX1 but THEX3 was the second best.

The ultimate economic requirement of this kind of process is the maximization of profit and minimization of product cost. It is therefore, imperative to use return on investment as an economic criteria for comparison among all hybrid configurations.

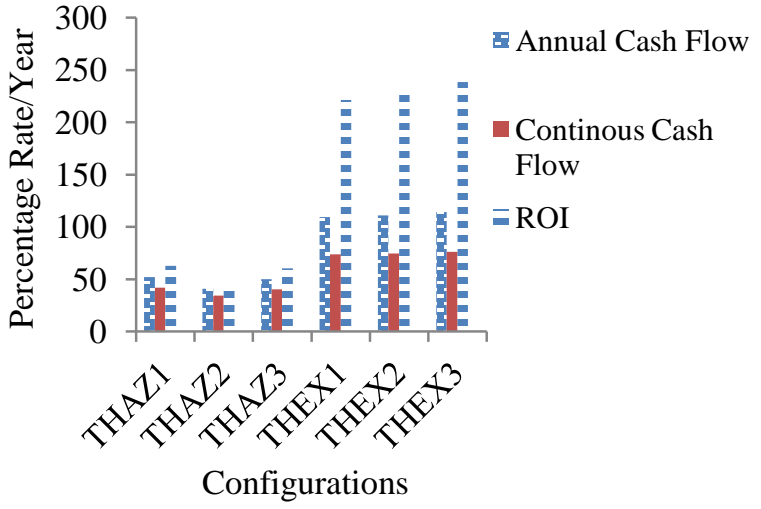

Figure 8. Return on Investment and Cash flow Rate for Hybrid Configurations

It is necessary to consider a trade-off between exergy and economic efficiency to draw conclusion as to which hybrid configuration is the most efficient. This is because the most exegetically efficient hybrid may be the most economically efficient. Looking at both sides, economic consideration takes precedence because of smaller difference of $0.9 \%$ in the exergetic efficiency between highest exergetic and most economic hybrid.

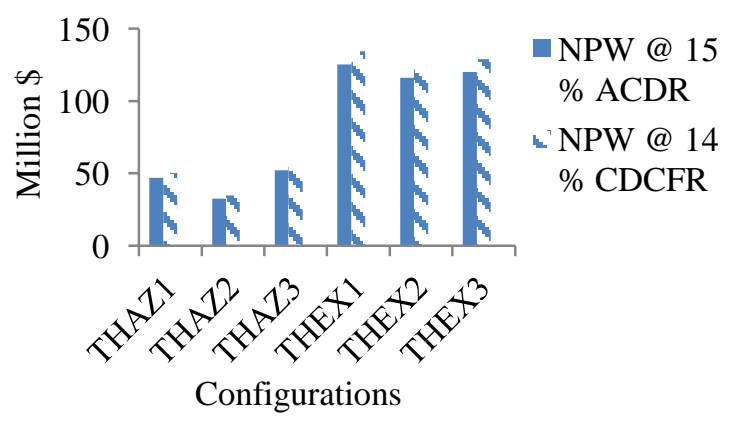

Figure 9. Hybrid Configurations Net Present worth

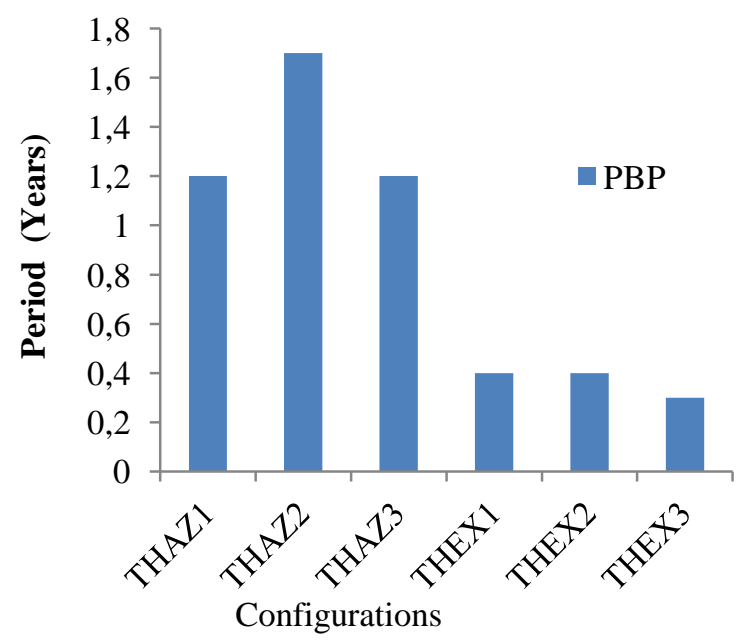

Figure 10. Hybrid Configurations Pay Back Period 


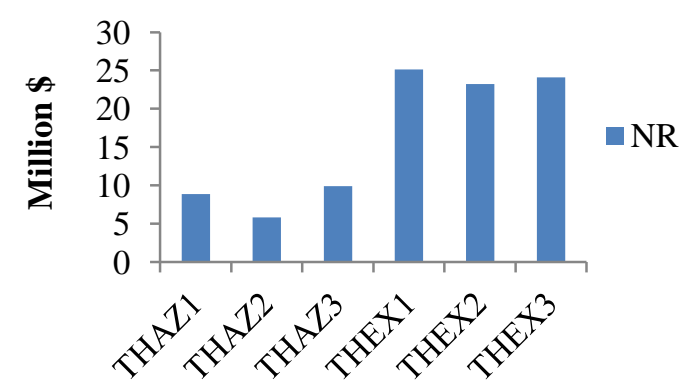

Configurations

Figure 11. Hybrid Configurations Net Return

Looking at energy, exergy and economic analysis together, THIDC-Thermally coupled extractive distillation hybrid is the best hybrid configuration of the six distillation hybrid configurations studied for bioethanol refining. This is because the hybrid was favoured from economic analysis and its energy consumption and irreversibility rate were very much close to the minimum obtainable among all the hybrid configurations.

\section{Conclusions}

The THIDC-extraction sequences were found to be better than the azeotropic distillation derived hybrids thermodynamically and economically. THEX1 recorded the highest exergy efficiency while THAZ2 was identified as the least efficient configuration.

It was also observed that the less energy consuming process might not necessarily be the most efficient configuration. However, economic analysis suggested the less energy consuming process THEX3 as the most attractive configuration that guarantee the production of affordable and sustainable fuel grade bioethanol.

Thermally coupled extractive distillation and THIDC hybrid is the preferred choice for commercial refining of bioethanol mash to fuel grade among all hybrid configurations considered in this work. Savings in energy cost of as much as $71 \%$ was achieved for THEX hybrids over similar configurations used in an earlier work. Utility energy input cost improvement was as high as 49 and $32 \%$ for THEX and THAZ hybrids respectively, when compared to reported works.

\author{
Nomenclature \\ APS Annual product sales \\ AZ1 Azeotropic distillation with recycle stream mixing \\ and entering with organic phase \\ AZ2 Azeotropic distillation with recycle stream mixing \\ and entering with feed \\ AZ3 THIDC-Azeotropic distillation with recycle \\ CDCFR Continuous discounted cash flow rate \\ ADCFR Annual discounted cash flow rate \\ CEPCI Chemical engineering cost index \\ Conv. Conventional \\ EX1 Conventional Extractive Distillation \\ EX2 Petlyuk Extractive Distillation \\ EX3 Thermally Coupled Extractive Distillation \\ FCI Fixed Capital Investment \\ NR Net Return \\ NPW Net Present Worth \\ PBP Payback Period \\ ROI Return on Investment
}

TAPC Total annual product cost

TCI Total capital investment

THAZ1 THIDC-Azeotropic distillation with recycle stream THAZ2 THIDC-Azeotropic distillation with recycle stream mixing and entering with feed

THAZ3 THIDC-Azeotropic distillation with recycle stream entering into decanter

THEX1 THIDC-Conventional extractive distillation

THEX2 THIDC-Petlyuk extractive distillation

THEX3 THIDC Thermally Extractive Distillation

THIDC Totally heat integrated distillation column

TUC Total annual utility cost

WC Working capital

\section{References}

[1] Bastidas, P.A., Gil, I.D. and Rodriguez, G. (2010). Comparison of the Main Ethanol Dehydration Technologies through Process Simulations. In 20th European Symposium on Computer Aided Process Engineering-ESCAPE-20, Ischia, Italy.

[2] Vascncelos, C.J.G., Wolf-Maciel, M.R. (2002). Optimization, Dynamics and Control of a Complete Azeotropic Distillation: New Strategies and stability Consideration. Distillation and Absorption Conference, Baden-Baden 6-28, 2002

[3] Watanabe, D., Wu, H., Noguchi, C., Zhou, Y., Akao, T., and Shionoi, H. (2010). Enhancement of the initial rate of ethanol fermentation due to dysfunction of yeast stress response components Msn2p and/orMsn4p. J. Applied and Environmental microbiology, 77, 934-941.

[4] Jeong, J., Jeon, H., Ko, K., Chung, B., and Choi, G. (2012). Production of Anhydrous Ethanol Using Various Pressure Swing Adsorption Processes in Pilot Plant. Renewable Energy J., 42, 41-45.

[5] Demirel, Y. (2004). Thermodynamics Analysis of Separation Systems. J. Separation Science and Technology, 39, 3897-3942.

[6] Bremers, G., Birzietis, G., Blija, A., Skele, A., Rucins, A. and Danilevics, A. (2010). Evaluating Usability of Water Adsorption and Rectification in Dehydration of Bioethanol. Jelgava 2010: Proceedings of $9^{\text {th }}$ International Scientific Conference of Engineering for Rural development, 154-157.

[7] Gil, I.D., Uyazan, A.M., Aguilar, J.L., Rodriguez, G., and Caicedo, L.A. Simulation of Ethanol Extractive Distillation with a Glycols Mixture as Entrainer. In 2nd Mercosur Congress on Chemical Engineering \& 4th Mercosur Congress on Process Systems Engineering, Braga, Portugal, September 4-6, 2008.

[8] Sanchez, O.J., Moncada, J.A., and Cardona, C.A. (2006). Modeling and Simulation of Ethanol Dehydration by Pervaporation and Energy Analysis of Separation Schemas for Fuel Ethanol Production. In Int. Congress of Chemical and Process Engineering

[9] Torres-Ortega, C.E., Segovia-Hernandez,J.G., Harnandez, S., Hernandez, H., Bonilla-Petriciolet A.B. and Maya-Yescas, R. Design and Optimization of Thermally Coupled Distillation Sequences for Purification of Bio-ethanol. PSE2009: In 10 
International Symposium on Process Systems Engineering, 957-962. Salvador-Bahia, Brazil August 16-20, 2009.

[10] Bremers, G., Birzietis, G., Blija, A., and Danilevics, A., and Skele, A. Scheme of Technology for Congruent Dehydration of Bioethanol in Semi-Dry Way. 2011: Proceedings of $10^{\text {th }}$ International Scientific Conference of Engineering for Rural development, 244-247. Jelgava 2011

[11] Carmo,M.J. and Gubulin, J.C. (1997). Ethanol Water Adsorption on Commercial 3A zeolites: Kinetic and Thermodynamic data. Brazilian Journal of Chemical Engineering, 14, 1-17.

[12] Pruksathorn, P. and Vitidsant, T. (2009). Production of Pure Ethanol from Azeotropic Solution by Pressure Swing Adsorption. American J. Engineering and Applied Sciences, 2, 1-7.

[13] Sohel, M.I. and Jack, M.W. Thermodynamic Analysis and Potential Improvements of a Biochemical Process for Lignocellulosic Biofuel Production. In World Renewable Energy Congress, Linköping, Sweden, 813 May 2011.

[14] Naidu Y. and Malik R.K. (2011). Generalized Methodology for Optimal Configurations of Hybrid Distillation-Pervaporation Processes. J. Chemical Engineering Research and Design; 89, 1348-1361.

[15] Verhoef A., Degreve J., Huybrechs B., Veen H., Pex P and Bruggn B.V. (2008). Simulation of a Hybrid Pervaporation-Distillation Process. J. Computers and Chemical Engineering, 32, 1135-1146.

[16] Kunnakorn D., Rirksomboon T., Siemanond K., Aungkavattana P., Kuanchertchoo N., Chuntanalerg P., Hemra K., Kulprathipanja S., James R.B, Wongkasemjit S. (2013). Techno-economic comparison of energy usage between azeotropic distillation and hybrid system for water-ethanol separation. Renewable Energy, 51, 310-316.

[17] Salvador H. (2008). Analysis of Energy-Efficient Complex Distillation Options to Purify Bioethanol, Chem. Eng. Technology, 31(4), 597-603.

[18] Errico M., Giuseppe T., Ben-Guang R., Daniele D., Ilkka T. (2009). Energy Saving and Capital Cost Evaluation in Distillation Column Sequences with a Divided Wall Column. Chemical Engineering Research and Design, 87, 1649-1657.

[19] Suleiman, B. Exergetic-economic assessment of Bioethanol Refining Configurations. MSc. Thesis Unpublished, Department of Chemical Engineering, Ahmadu Bello University, Zaria, Nigeria, 2014.

[20] Neagu M., Cursaru D. (2013). Bioethanol dehydration by Extractive Distillation with Propylene Glycol Entrainer (A preliminary case study). REV. CHIM (Bucharest), 64, 92-94.

[21] Querel, E., Gonzaliz-Reguerel, B., and Perez-Benedito, J.L. (2013). Practical Approach to Energy and Thermoeconomic Analysis of Industrial Processes, $\left(1^{\text {st }}\right.$ ed.). London Heidelberg: Springer London.
[22] Seader J.D., Henley E.J. and Roper D.K. Separation Process Principles, ( $3^{\text {rd }}$ Ed.). Hoboken United State of America: John Wiley and Sons. Inc., 2011

[23] Dincer, I. and Naterer G.F. (2010). Assessment of Exergy Efficiency and Sustainability Index of an AirWater Heat Pump. International J. Exergy, 7, 37-50.

[24] Peters M.S., Timmerhaus K.D. Plant Design and Economics for Chemical Engineers (4 ${ }^{\text {th }}$ ed.). New York: McGraw-Hill Inc., 1991.

[25] Bandyopadhyay, S. (2002). Effect of Feed on Optimal Thermodynamic Performance of a Distillation Column. J Chem. Eng., 88, 175-186.

[26] Wolf Maciel, M.R., (2009), Advances in ethanol purification: alternatives and perspectives. Retrieved from http://www.fapesp.br/eventos/2009/09/10_bioen _Regina.pdf

[27] Online process equipment calculator. Peters and Timmerhaus (1991). Retrieved June 12, 2012 from http://www.higheredmcgrawhill.com/sites/0072392665 /student_view0/cost_estimator.html 